\title{
Functional Specificity of Long-Range Intrinsic and Interhemispheric Connections in the Visual Cortex of Strabismic Cats
}

\author{
Kerstin E. Schmidt, ${ }^{1}$ Dae-Shik Kim, ${ }^{2}$ Wolf Singer, ${ }^{1}$ Tobias Bonhoeffer, ${ }^{3}$ and Siegrid Löwel ${ }^{1}$ \\ ${ }^{1}$ Max-Planck-Institut für Hirnforschung, Abteilung Neurophysiologie, D-60528 Frankfurt AM, Germany, ${ }^{2}$ Laboratory for \\ Neural Modeling, Frontier Research Program, The Institute for Physical and Chemical Research, Wako, Saitama 351-01, \\ Japan, and ${ }^{3}$ Max-Planck-Institut für Psychiatrie, D-82152 München-Martinsried, Germany
}

The development of both long-range intracortical and interhemispheric connections depends on visual experience. Previous experiments showed that in strabismic but not in normal cats, clustered horizontal axon projections preferentially connect cell groups activated by the same eye. This indicates that there is selective stabilization of fibers between neurons exhibiting correlated activity. Extending these experiments, we investigated in strabismic cats: (1) whether tangential connections remain confined to columns of similar orientation preference within the subsystems of left and right eye domains; and (2) whether callosal connections also extend predominantly between neurons activated by the same eye and preferring similar orientations. To this end, we analyzed in strabismic cats the topographic relationships between orientation preference domains and both intrinsic and callosal connections of area 17. Red and green latex microspheres were injected into monocu- lar iso-orientation domains identified by optical imaging of intrinsic signals. Additionally, domains sharing the ocular dominance and orientation preference of the neurons at the injection sites were visualized by 2-deoxyglucose (2-DG) autoradiography. Quantitative analysis revealed that $56 \%$ of the retrogradely labeled cells within the injected area 17 and $60 \%$ of the transcallosally labeled neurons were located in the 2-DG-labeled iso-orientation domains. This indicates: (1) that strabismus does not interfere with the tendency of long-range horizontal fibers to link predominantly neurons of similar orientation preference; and (2) that the selection mechanisms for the stabilization of callosal connections are similar to those that are responsible for the specification of the tangential intrinsic connections.

Key words: long-range intracortical connections; callosal connections; experience-dependent development; optical imaging; area 17; strabismus
Long-range tangential axon collaterals are a prominent feature of cortical circuitry (Fisken et al., 1975). In the mammalian visual cortex, they interconnect regularly spaced clusters of cells [tree shrew (Rockland and Lund, 1982), squirrel and macaque monkey (Rockland and Lund, 1983; Livingstone and Hubel, 1984), cat (Gilbert and Wiesel, 1983; Kisvárday and Eysel, 1992), and ferret (Rockland, 1985)], which share preferences for similar orientations or colors (Ts'o et al., 1986, 1988; Gilbert and Wiesel, 1989; Gray et al., 1989; Hata et al., 1991; Malach et al., 1993, 1994). It has been proposed that these connections: (1) contribute to the generation of large composite receptive fields (Singer and Tretter, 1976; Gilbert and Wiesel, 1985; Bolz and Gilbert, 1990, Schwarz and Bolz, 1991), (2) mediate inhibitory and subthreshold excitatory effects from beyond the classical receptive field (Blakemore and Tobin, 1972; Nelson and Frost, 1978; Morrone et al., 1982; Allman et al., 1985), (3) contribute to orientation and direction tuning (Eysel et al., 1987, 1990), (4) are responsible for adaptive changes of cortical maps after deafferentiation (Kaas et al., 1990; Heinen and Skavenski, 1991; Gilbert and Wiesel, 1992; DarianSmith and Gilbert, 1994), and (5) synchronize the responses of

\footnotetext{
Received Dec. 10, 1996; revised April 8, 1997; accepted May 1, 1997.

We thank E. Raulf and M. Sum for excellent technical assistance, M. Stephan for programs, the staff of the animal house for excellent animal care, the darkroom team for photographs, and R. Ruhl for preparing illustrations. We are also grateful to R. Galuske, J.-C. Houzel, and P. Roelfsema for helpf ul discussion.

Correspondence should be addressed to Kerstin E. Schmidt, Max-Planck-Institut für Hirnforschung, Abteilung Neurophysiologie, Deutschordenstraße 46, D-60528 Frankfurt AM, Germany.

Copyright (C) 1997 Society for Neuroscience $\quad 0270-6474 / 97 / 175480-13 \$ 05.00 / 0$
}

spatially distributed neurons as a function of stimulus coherence (Gray et al., 1989; König et al., 1993; Singer, 1993).

In kitten visual cortex, tangential fibers develop mainly after birth and attain their adult specificity within the first 6-8 weeks (Luhmann et al., 1986; Price 1986; Callaway and Katz, 1990; Galuske and Singer, 1996). The refinement of the architecture of these connections depends on visual experience (Callaway and Katz, 1991; Luhmann et al., 1991) whereby extension and elimination of collaterals overlap in time (Callaway and Katz, 1991; Galuske and Singer, 1996). Direct evidence for the hypothesis that connections are stabilized selectively between cells exhibiting correlated activity was obtained in strabismic cats. In these animals, the segregation of geniculocortical afferents in layer IV is accentuated (Shatz et al., 1977; Löwel, 1994), and most neurons become monocular, responding exclusively either to the left or right eye (Hubel and Wiesel, 1965). In addition, tangential intracortical fibers come to preferentially connect cell groups activated by the same eye (Löwel and Singer, 1992).

Callosal connections share a number of features with the intracortical horizontal connections. They originate from and terminate on similar classes of cells in supragranular and infragranular layers, are reciprocal, and exhibit topological specificity (for review, see Innocenti, 1986). Neurons located close to the representation of the vertical meridian have receptive fields that cross the midline of the visual field, and the responses to stimuli in the ipsilateral hemifield are conveyed by callosal input. The ipsilateral and contralateral moieties of the crossing receptive fields have the same orientation and direction preference (Berlucchi and Rizzolatti, 1968; Lepore and Guillemot, 1982; Blakemore et al., 1983), 
suggesting that the orientation preference of the callosal afferents is matched with that of their respective target cells. Callosally projecting neurons in sensory, motor, and association areas of many species exhibit a columnar distribution (for review, see Innocenti, 1986), and the axon arbors of callosal neurons are patchy (Houzel et al., 1994), suggesting a relation with functional columns. As the horizontal intracortical fibers, visual callosal connections also can be modified by manipulating early visual experience. In the cat, callosal axons are initially imprecise and exuberant and attain their adult specificity by elimination of ectopic axon terminals (Innocenti and Caminiti, 1980). This process seems to be influenced by activity, because early onset strabismus, monocular deprivation, and short periods of binocular deprivation lead to preservation of ectopic connections (Lund et al., 1978; Innocenti and Frost, 1979; Cynader et al., 1981; Berman and Payne, 1983; Elberger et al., 1983). Thus, both tangential intrinsic fibers and callosal connections exhibit a high degree of selectivity in the adult, and both projections are susceptible to experience-dependent modifications. Because it is established that the former get selected by activity according to a correlation rule, we wondered whether the same is true also for callosal connections. If so, the prediction is that in strabismic animals, callosal connections should become confined to link territories of same eye dominance selectively. Moreover, their selectivity with respect to the orientation preference of interconnected cortical domains should be affected by squint in the same way, if at all, as that of the intrinsic tangential connections. To test these predictions we first examined whether divergent strabismus had any effect on the tendency of the intrinsic connections to link domains with similar orientation preference selectively. In addition, we studied in the same strabismic cats the selectivity of callosal connections with respect to the ocular dominance and orientation preference of the interconnected domains.

\section{MATERIALS AND METHODS}

In this study eight cats from the colony of our institute were used. Six of them (cats C1-C6) were raised with surgically induced divergent strabismus, and two of them (cats $\mathrm{CN}$ and $\mathrm{CC}$ ) had normal visual experience.

Induction of squint. In the cats C1-C6 divergent strabismus was induced surgically at the age of $17-18 \mathrm{~d}$ by severing the tendon of the medial rectus muscle of the left eye. Two of these animals were from the same litter (C4 and C5). For surgery, kittens were anesthetized with an intramuscular injection of ketamine hydrochloride $(10 \mathrm{mg} / \mathrm{kg}$; Ketanest, Parke-Davis) and xylazine hydrochloride (2.5 mg/kg; Rompun, Bayer).

We used the corneal reflex method (Sherman, 1972; Olson and Freeman, 1978; von Grünau, 1979) to check the effectiveness of squint induction. The kittens were restrained manually, and flashlight snapshots were taken weekly until the kittens were 2 months old. The distances between the corneal reflexes and the pupils were measured on the photo prints, and the ratio of the reflex distance over the pupillary distance was used as an indicator of eye alignment (Sherman, 1972; von Grünau, 1979; Sireteanu et al., 1993). The ratios measured in our animals were in the strabismic range throughout the critical period $(<0.93$ according to Sireteanu et al., 1993): C1, $0.88 \pm 0.03$ (mean \pm SD); C2, $0.88 \pm 0.02 ; C 3$, $0.89 \pm 0.02$; C4, $0.88 \pm 0.02$; C5, $0.91 \pm 0.02$; and C6, $0.90 \pm 0.03$. Thus, all our squinting cats exhibited manifest exotropia.

Optical imaging. Optical imaging was performed in all cats except cat $\mathrm{CC}$ to guide tracer injections. In cat $\mathrm{CC}$ the tracers were injected blind, and the ocular dominance was determined later by inspection of the cortical 2-DG autoradiographs and tracer uptake in the lateral geniculate nucleus.

At the age of 2-3 months, the functional architecture of area 17 was visualized using optical imaging of intrinsic signals (Grinvald et al., 1986) as described in detail by Bonhoeffer and Grinvald (1993). Anesthesia was induced as described above (ketamine and xylazine) and, after tracheal intubation and cannulation of a humeral vein, was maintained by ventilating the cat with a mixture of $70 \% \mathrm{~N}_{2} \mathrm{O}$ and $30 \% \mathrm{O}_{2}$ supplemented by
0.4-1\% halothane (Hoechst Pharmaceuticals, Frankfurt, Germany). Images were taken from the right cortex of cats $\mathrm{C} 1, \mathrm{C} 2, \mathrm{C} 3, \mathrm{C} 5$, and $\mathrm{CN}$ and the left cortex of cats $\mathrm{C} 4$ and C6. Visual stimuli were generated with a monitor $(25 \times 33 \mathrm{~cm})$ positioned at a distance of $25 \mathrm{~cm}$ in front of the animals, covering about $65^{\circ}$ of the visual field. The cat's eyes were refracted accordingly and fitted with corneal contact lenses containing artificial pupils of $3 \mathrm{~mm}$. Stimuli consisted of high-contrast square wave gratings of four different orientations $\left(0,45,90\right.$, and $\left.135^{\circ}\right)$ with a spatial frequency of 0.5 cycles (cyc) $/{ }^{\circ}$ and a drift velocity of $4^{\circ} / \mathrm{sec}$. Monocular visual stimulation of the cats was achieved with computer-controlled eye shutters.

Tracer injection. At the end of the optical recording session, rhodamine- and fluorescein-conjugated latex microspheres ("red and green beads," Luma Fluor) (Katz et al., 1984; Katz and Iarovici 1990) were pressure-injected into the center of orientation domains located within territories dominated by either the right or the left eye. Two injections were made in each experiment, one with green beads and the other with red beads, both being aimed into columns of the same eye and same orientation preference to obtain two samples of one condition per animal (Fig. 1). In cat $\mathrm{CN}$, which was raised normally, injections were made in binocular domains of the right hemisphere with orientation specificities orthogonal (green beads, $90^{\circ}$; red beads, $0^{\circ}$ ) to each other. Using the vascular pattern as a reference, all injections were placed into cortical regions with unambiguous orientation and eye preference as inferred from the respective optical activity maps. Cat $\mathrm{CC}$ received two blind injections in left area 17 at Horsley-Clarke (1908) coordinates posterior 3 and lateral 4. A glass micropipette (tip diameter, $25 \mu \mathrm{m}$ ) filled with beads was attached to a micromanipulator and lowered 600-1000 $\mu \mathrm{m}$ into the cortex perpendicular to the cortical laminae, and about 0.25 $\mu l$ of the microsphere suspension was pressure-injected. Injection sites were restricted to the gray matter and confined to area 17 as confirmed by the distribution of retrogradely labeled cells in the lateral geniculate nucleus (see Fig. 3). The size of the injection sites ranged from 150 to 400 $\mu \mathrm{m}$ in diameter (Table 1) as measured in representative cortical sections.

2-Deoxyglucose autoradiography and histological procedures. Four to $5 \mathrm{~d}$ after the tracer injections, domains sharing the ocular dominance and orientation specificity of the injection sites were additionally labeled by 2 - $\left[{ }^{14} \mathrm{C}\right]$ deoxyglucose autoradiography. Anesthesia was induced and maintained as described above and supplemented by a muscle relaxant (Flaxedil, gallamine triethiodide, $160 \mathrm{mg}$ in $50 \mathrm{ml}$ of saline, 3 $\mathrm{ml} \cdot \mathrm{kg}^{-1} \cdot \mathrm{hr}^{-1}$; Specia) to prevent eye movements. All strabismic animals (cats C1-C6) were stimulated monocularly through the eye that dominated the neurons at the injection site. The respective nonstimulated eye (left eye in cats $\mathrm{C} 1, \mathrm{C} 2, \mathrm{C} 3$, and $\mathrm{C} 5$; right eye in cats $\mathrm{C} 4$ and $\mathrm{C} 6$ ) was covered with a black contact lens and an additional black patch. Simultaneously with the onset of the visual stimulation, the cats received an intravenous injection of 2-deoxy-D-[U- $\left.{ }^{14} \mathrm{C}\right]$ glucose $($ dose, $100 \mu \mathrm{Ci} / \mathrm{kg}$; specific activity, $295 \mu \mathrm{Ci} / \mathrm{mmol}$; Amersham). Visual stimuli were the same as those used for optical imaging, except that only the orientation was presented that was preferred by the neurons at the injection sites. The normal cat $\mathrm{CN}$ was stimulated binocularly with horizontal gratings $\left(0^{\circ}\right)$. Because in normally reared animals ocular dominance territories can only be mapped with the 2-DG method if the animals are awake during monocular stimulation (Löwel and Singer, 1992, 1993b), cat CC had a venous catheter implanted under halothane anesthesia (see above for mixture), and the left eye occluded as described above. After full recovery from anesthesia, $2-\mathrm{DG}$ was injected, and the cat was allowed to move around freely for effective monocular stimulation with contours of all orientations. This experimental paradigm is known to label ocular dominance domains effectively in normally reared cats (Löwel and Singer, 1992, 1993b).

After 45 min of visual stimulation, the animals received a lethal dose of pentobarbital $(180 \mathrm{mg} / \mathrm{kg}$, Nembutal) injected intravenously. The occipital poles and the lateral geniculate nuclei (LGN) of the brain were removed. The LGN was frozen in methylbutane cooled to $-35^{\circ} \mathrm{C}$. The visual cortices were flat-mounted (Freeman et al., 1987; Löwel et al., 1987) before freezing the tissue on dry ice. To provide landmarks for later superposition, three holes were melted into the flat mounts with warm needles. Subsequently, 26- $\mu$ m-thick serial cryostat sections were cut at $-16^{\circ} \mathrm{C}$. Blocks containing the visual cortex were cut parallel to the cortical surface; those containing the LGN were cut in the frontal plane. Sections were mounted on glass slides, dried on a hot plate, and then exposed to x-ray film (Structurix D7W, Agfa Gevaert) for 3-4 weeks.

Data analysis and image processing. The distributions of labeled neurons, injection sites, and landmarks were mapped with a Zeiss fluores- 


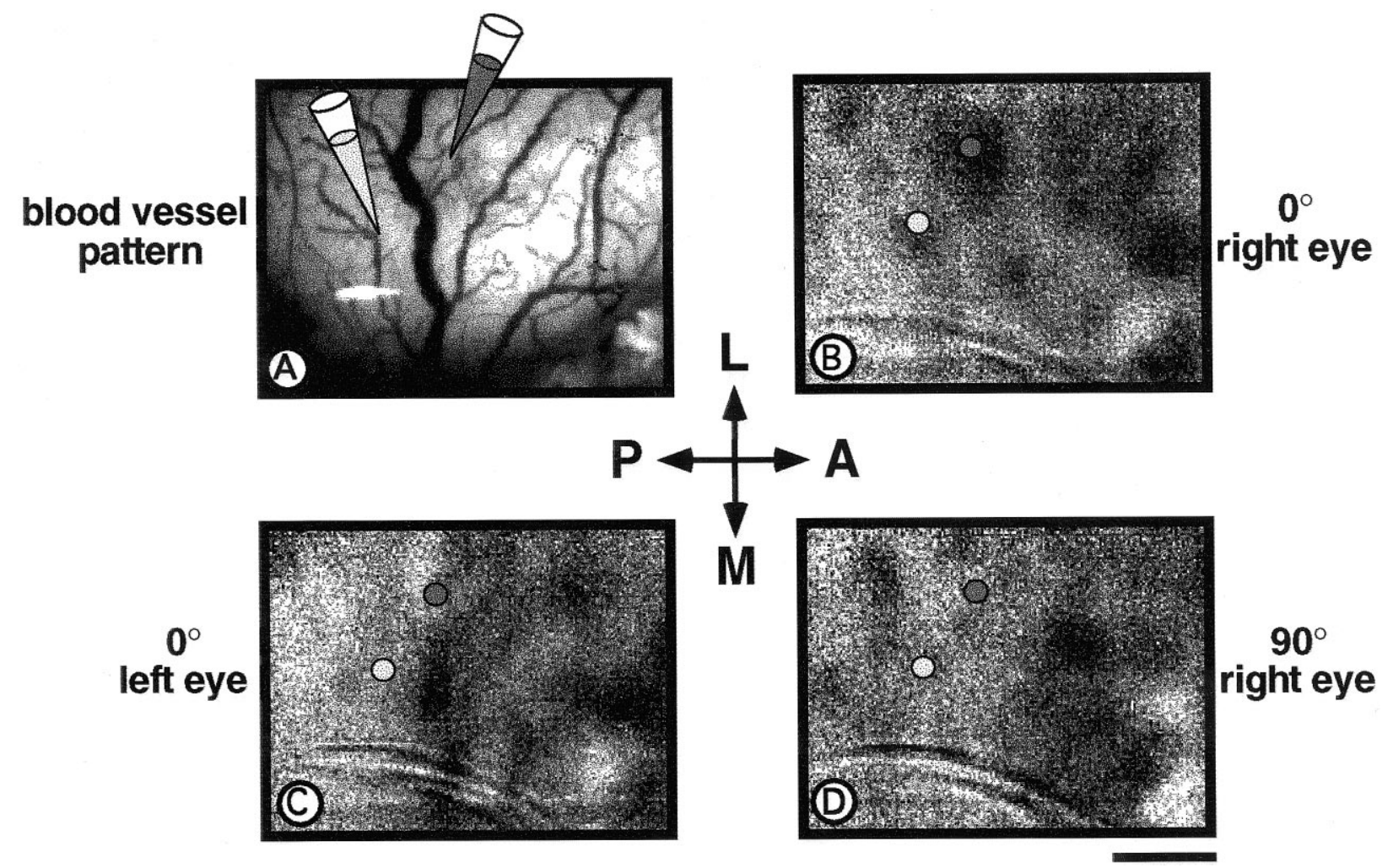

Figure 1. Monocular orientation preference domains in left area 17 of a strabismic cat (C2), visualized by optical imaging of neuronal activity. The animal was stimulated monocularly with oriented bars of $0^{\circ}$ (horizontal), 45 and $90^{\circ}$ (vertical), and $135^{\circ}\left(4^{\circ} / \mathrm{sec}, 0.5 \mathrm{cyc} /{ }^{\circ}\right)$. $A$, Blood vessel pattern. $B-D$, Activation patterns evoked with horizontal contours from the right $(B)$ and left $(C)$ eyes and with vertical contours from the right eye $(D)$. Injection sites of red and green beads are indicated by dark (red injection) and light (green injection) arrowheads $(A)$ or dark and light dots, respectively $(B-D)$. Injections were targeted to horizontal orientation columns activated through the right eye shown in $B$. Note that the injection sites were localized in "nonactive" regions in the $0^{\circ}$ left eye $(C)$ and the $90^{\circ}$ right eye $(D)$ stimulus conditions. Cortical coordinates: $P$, posterior; $L$, lateral; $A$, anterior; $M$, medial. Scale bar, $1 \mathrm{~mm}$.

Table 1. Distribution of retrogradely labeled neurons in laminae A, A1, and C and the medial interlaminar nucleus of the lateral geniculate nucleus

\begin{tabular}{|c|c|c|c|c|c|}
\hline $\begin{array}{l}\text { Cat (color of } \\
\text { injection) }\end{array}$ & $\begin{array}{l}\text { Labeled } \\
\text { neurons }(n)\end{array}$ & $\begin{array}{l}\text { Lamina A } \\
(\%)\end{array}$ & $\begin{array}{l}\text { Lamina AI } \\
(\%)\end{array}$ & $\begin{array}{l}\text { Lamina C } \\
(\%)\end{array}$ & $\begin{array}{l}\text { Medial in- } \\
\text { terlaminar } \\
\text { nucleus }(\%)\end{array}$ \\
\hline $\mathrm{C} 1$ (green) & 154 & 61.7 & 5.2 & 29.2 & 3.9 \\
\hline $\mathrm{C} 1$ (red) & 306 & 46.7 & 22.5 & 26.8 & 4.0 \\
\hline C2 (green) & 157 & 31.2 & 0 & 63.7 & 5.1 \\
\hline C2 (red) & 18 & 36.0 & 0 & 55.0 & 9.0 \\
\hline C3 (green) & 124 & 31.5 & 0 & 60.5 & 8.0 \\
\hline C3 (red) & 197 & 63.8 & 0 & 31.9 & 4.3 \\
\hline C4 (green) & 445 & 42.5 & 28.2 & 26.7 & 2.6 \\
\hline C5 (green) & 186 & 55.4 & 22.1 & 22.5 & 0 \\
\hline C5 (red) & 110 & 48.2 & 22.8 & 29.0 & 0 \\
\hline C6 (green) & 136 & 27.9 & 42.6 & 27.3 & 2.2 \\
\hline C6 (red) & 30 & 0 & 13.3 & 86.7 & 0 \\
\hline $\mathrm{CN}$ (green) & 210 & 43.0 & 36.0 & 21.0 & 0 \\
\hline $\mathrm{CN}$ (red) & 145 & 34.2 & 50.8 & 15.0 & 0 \\
\hline CC (green) & 425 & 10.0 & 80.0 & 10.0 & 0 \\
\hline $\mathrm{CC}$ (red) & 188 & 10.0 & 81.0 & 9.0 & 0 \\
\hline
\end{tabular}

${ }^{a}$ Color of the fluorescent microspheres used for tracer injection.

cence microscope equipped with a computer-controlled $\mathrm{x} / \mathrm{y}$ stage driven by the analysis program Magellan (Halasz and Martin, 1984). Cells were usually plotted at 100-fold magnification (objective, $10 \times$ ); however, we always assured with a higher magnification (objective, $16 \times$ ) that weakly labeled cells were not missed. For the analysis of intracortical circuitry, five to eight sections from each hemisphere were analyzed quantitatively.
Usually, cells in the immediate vicinity of the injection sites were not plotted, because the intense fluorescence did not allow proper discrimination of labeled cells. In hemispheres contralateral to the injection sites, callosally projecting neurons were found in 6-12 successive sections of supragranular and granular layers. For quantitative analysis, every second section was plotted. 
Table 2. Intrinsic connections in area 17

\begin{tabular}{|c|c|c|c|c|c|c|c|c|c|}
\hline \multirow[b]{2}{*}{ Cat } & \multirow[b]{2}{*}{$\begin{array}{l}\text { Color of } \\
\text { injection }^{a}\end{array}$} & \multirow[b]{2}{*}{ Weight (gm) } & \multirow[b]{2}{*}{$\begin{array}{l}\text { Age } \\
\text { (weeks) }\end{array}$} & \multirow[b]{2}{*}{$\begin{array}{l}\text { Injection } \\
\text { size }\left(\mu \mathrm{m}^{2}\right)\end{array}$} & \multirow[b]{2}{*}{$\begin{array}{l}\text { Analyzed } \\
\text { sections }(n)\end{array}$} & \multirow{2}{*}{$\begin{array}{l}\text { OD/OR of labeled } \\
\text { area/relative part of } \\
\text { the cortical surface } \\
(\%)\end{array}$} & \multirow{2}{*}{$\begin{array}{l}\text { OD/OR of } \\
\text { injection } \\
\text { site }\end{array}$} & \multicolumn{2}{|c|}{ Labeled neurons $[n(\%)]$} \\
\hline & & & & & & & & Inside & Outside \\
\hline $\mathrm{C} 1$ & Green & 1240 & 12.5 & $300 \times 300$ & 4 & $90^{\circ} / \mathrm{ri}(30)$ & $90^{\circ} / \mathrm{ri}$ & $583(54.3)$ & $490(45.7)$ \\
\hline $\mathrm{C} 1$ & Red & 1240 & 12.5 & $200 \times 300$ & 4 & $90^{\circ} /$ ri $(30)$ & $90^{\circ} / \mathrm{ri}$ & $765(56.3)$ & $593(43.7)$ \\
\hline $\mathrm{C} 2$ & Green & 1040 & 10 & $300 \times 200$ & 5 & $0^{\circ} / \mathrm{ri}(30)$ & $0^{\circ} / \mathrm{ri}$ & $888(56.4)$ & $686(43.6)$ \\
\hline $\mathrm{C} 2$ & Red & 1040 & 10 & $300 \times 150$ & 5 & $0 \%$ ri $(30)$ & $0^{\circ} / \mathrm{ri}$ & $204(71.3)$ & $82(28.7)$ \\
\hline $\mathrm{C} 3$ & Green & 600 & 7 & $100 \times 200$ & 6 & $0^{\circ} / \mathrm{ri}(30)$ & $0^{\circ} / \mathrm{ri}$ & $388(57.9)$ & $282(42.1)$ \\
\hline $\mathrm{C} 3$ & Red & 600 & 7 & $250 \times 250$ & 6 & $0 \%$ ri (30) & $0^{\circ} / \mathrm{ri}$ & $677(45.8)$ & $800(54.2)$ \\
\hline $\mathrm{C} 4$ & Green & 550 & 7.5 & $300 \times 200$ & 5 & $135^{\circ} / \mathrm{ri}(30)$ & $135^{\circ} / \mathrm{le}$ & $873(52.3)$ & $797(47.7)$ \\
\hline $\mathrm{C} 5$ & Green & 800 & 8 & $200 \times 300$ & 7 & $45^{\circ} /$ le $(30)$ & $45^{\circ} / \mathrm{le}$ & $1479(59.8)$ & $993(40.2)$ \\
\hline $\mathrm{C} 5$ & Red & 800 & 8 & $300 \times 200$ & 7 & $45^{\circ} /$ le $(30)$ & $45^{\circ} / \mathrm{le}$ & $492(49.1)$ & $511(50.9)$ \\
\hline $\mathrm{CN}$ & Green & 800 & 10 & $300 \times 300$ & 5 & $0^{\circ} / \mathrm{bi}(30)$ & $90^{\circ} / \mathrm{bi}$ & $690(20.8)$ & $2555(88.4)$ \\
\hline $\mathrm{CN}$ & Red & 800 & 10 & $150 \times 200$ & 5 & $0 \%$ bi (30) & $0^{\circ} / \mathrm{bi}$ & $1132(56.0)$ & $743(39.6)$ \\
\hline $\mathrm{CC}$ & Green & 1100 & 10 & $350 \times 250$ & 4 & $0,45,90,135^{\circ} /$ le $(50)$ & $\mathrm{Lab} / \mathrm{le}$ & $719(59.7)$ & $728(40.3)$ \\
\hline $\mathrm{CC}$ & Red & 1100 & 10 & $200 \times 200$ & 4 & $0,45,90,135^{\circ} /$ le $(50)$ & $\mathrm{Lab} / \mathrm{le}$ & $146(54.1)$ & $185(45.9)$ \\
\hline
\end{tabular}

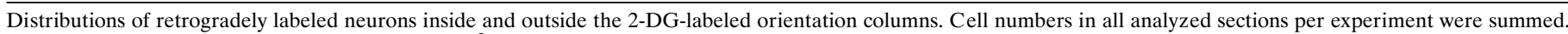

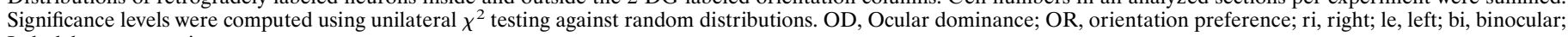
Lab, laboratory environment.

${ }^{a}$ Color of the fluorescent microspheres used for tracer injection.

For data presentation, autoradiographs were contrast-enhanced with an image-processing system (Imago II, Compulog) by expanding the gray values. For image processing, the optical density of the autoradiographs was translated into gray values. These are in arbitrary units ranging from 0 (black) to 255 (white). Large scale inhomogeneities in the optical density distributions were compensated by high-pass filtering of the digitized images.

The cell plots and the 2-DG autoradiographs of the same section were superimposed with the aid of the plotted landmarks. For quantitative analysis, $30 \%$ of the pixels with the lowest gray values (highest optical density) were displayed black (gray value 0 , on a scale ranging from 0 to 255) and considered as the domain that showed the same ocular dominance and orientation preference as the injection site; the remaining $70 \%$ were displayed white (gray value 255) (Fig. 3D). This thresholding procedure had the effect that the labeled domain occupied $30 \%$ of the cortical surface. This particular value was chosen for two reasons. First, visual assessment of borders between active and inactive regions in both optical imaging and 2-deoxyglucose patterns suggested that active zones occupied approximately $30 \%$ of the cortical surface. Second, the gray value histograms of all investigated autoradiographs could be approximated by a composite of two gaussian functions, the steeper one with its maximum at low gray values (high optical density) reflecting most likely the signal and the more shallow one the noise. Characteristically, about $30 \%$ of the pixels with the lowest gray values were located on the left side of the intersection point of these two functions. For cat $\mathrm{CC}$, which received 2-DG while awake, all orientations were visible; therefore, the threshold was set to $50 \%$, assuming that both eyes occupy cortical territories of equal size. Retrogradely labeled neurons were classified into two groups depending on their location on the 2-DG patterns: (1) neurons within and (2) neurons outside the labeled domains. The distributions of labeled neurons differed by less than $\pm 6.5 \%$ from the mean between different sections. For quantification, cells in the respective domains were pooled over all plotted sections of one experiment (Table 1). In the case of the callosal connections, distributions from different sections were summed because of small cell numbers (Table 2). For statistical analysis, we normalized the cell numbers relative to the area occupied by the domains sharing the functional properties of the injection site. Absolute numbers of cells in the respective compartments were divided by the relative size of the compartment ( 0.3 and 0.7 , respectively) and than multiplied by 0.5 to keep cell numbers unchanged. The resulting numbers reflect the relative cell densities in the two regions separated by the thresholding equation. The $\chi^{2}$ test was applied to the normalized distributions to test whether the distributions in the two regions were different from chance.

To determine the ocular dominance of the cells at the injection sites and their relative location to the area $17 / 18$ border, we inspected the cortical autoradiographs and additionally analyzed the laminar distribution of retrogradely labeled neurons in the LGN (Table 3). The 17/18 border was determined on the autoradiographs as the lateral border of the region containing labeled orientation domains, because for visual stimulation, we used slowly moving gratings of high spatial frequency $(0.5$ $\mathrm{cyc}^{\circ}{ }^{\circ}$ ) that are known to stimulate area 17 neurons preferentially.

LGN cell plots and the autoradiographs were aligned with the help of air bubbles. Because of the monocular stimulation protocol, laminar borders of the LGN could be distinguished on the 2-DG autoradiographs and were confirmed by additional Nissl staining of the tissue sections.

\section{RESULTS}

\section{Layout of monocular orientation domains in strabismic cats}

Monocular visual stimulation with gratings of a single orientation produced isolated patches of increased 2-DG uptake (Fig. 2A,B). This labeling pattern differs from that in normal cats, in which similar stimuli generated a pattern composed of beaded bands (Löwel et al., 1987; Löwel and Singer, 1993a). Another difference is that the optic disk representation of the contralateral eye is identifiable as an unlabeled region in the posterior third of area 17 (Löwel and Singer, 1993a) (Fig. 2). In agreement with 2-DG patterns obtained in normal cats after binocular stimulation with a single orientation (Albus, 1979; Singer, 1981; Löwel et al., 1987 Löwel and Singer, 1993a), 2-DG labeling in the strabismic cats extended in columns through the entire cortical thickness.

\section{Verification of the ocular dominance of injection sites}

The ocular dominance of the injection sites was deduced from the cortical autoradiographs. In addition, the laminar distribution of retrogradely labeled cells was analyzed in the LGN as described previously (Löwel and Singer, 1992). Distributions were determined in the left LGN of cats C1, C2, C3, C5, and CC and in the right LGN of cats $\mathrm{C} 4, \mathrm{C} 6$, and $\mathrm{CN}$ (see Table 1). In strabismic cats $\mathrm{C} 1-\mathrm{C} 5$, the majority of labeled neurons were located in medial lamina $\mathrm{C}$ (posterior sections) and in lamina A (anterior sections), sparing lamina A1. In cases C4 red and C6 green, $>40 \%$ of the cells were found in lamina A1. These injections were considered as not eye-specific and discarded from further analysis. The 
Table 3. Callosal connections

\begin{tabular}{|c|c|c|c|c|c|c|c|}
\hline \multirow[b]{2}{*}{ Cat } & \multirow{2}{*}{$\begin{array}{l}\text { Color of } \\
\text { injection }\end{array}$} & \multirow{2}{*}{$\begin{array}{l}\text { Analyzed } \\
\text { sections }(n)\end{array}$} & \multirow{2}{*}{$\begin{array}{l}\text { Medial ex- } \\
\text { tension of } \\
\text { labeled neu- } \\
\text { rons in area } \\
17(\mathrm{~mm})\end{array}$} & \multirow{2}{*}{$\begin{array}{l}\mathrm{OD} / \mathrm{OR} \text { of labeled } \\
\text { area/relative part of } \\
\text { cortical surface area } \\
(\%)\end{array}$} & \multirow{2}{*}{$\begin{array}{l}\mathrm{OD} / \mathrm{OR} \\
\text { of injec- } \\
\text { tion site }\end{array}$} & \multicolumn{2}{|c|}{ Labeled neurons $[n(\%)]$} \\
\hline & & & & & & Inside & Outside \\
\hline $\mathrm{C} 2$ & Green & 6 & 2.98 & $0^{\circ} / \mathrm{ri}(30)$ & $0^{\circ} / \mathrm{ri}$ & $56(63.6)$ & $32(36.4)$ \\
\hline $\mathrm{C} 2$ & Red & 3 & 2.67 & $0^{\circ} / \mathrm{ri}(30)$ & $0^{\circ} / \mathrm{ri}$ & $21(80.7)$ & $5(19.3)$ \\
\hline $\mathrm{C} 3$ & Green & 5 & 3.48 & $0^{\circ} / \mathrm{ri}(30)$ & $0^{\circ} / \mathrm{ri}$ & $74(63.8)$ & $42(36.2)$ \\
\hline $\mathrm{C} 3$ & Red & 5 & 2.5 & $0^{\circ} / \mathrm{ri}(30)$ & $0^{\circ} / \mathrm{ri}$ & $28(53.8)$ & $24(46.2)$ \\
\hline C5 & Green & 5 & 2.36 & $45^{\circ} /$ le $(30)$ & $45^{\circ} / \mathrm{le}$ & $11(52.4)$ & $10(47.6)$ \\
\hline C5 & Red & 5 & 3.63 & $45^{\circ} /$ le $(30)$ & $45^{\circ} / \mathrm{le}$ & $36(48.0)$ & $39(52.0)$ \\
\hline $\mathrm{CC}$ & Green & 11 & 2.70 & $0,45,90,135^{\circ} /$ le $(50)$ & $\mathrm{Lab} / \mathrm{le}$ & $215(60.3)$ & $141(39.7)$ \\
\hline $\mathrm{CC}$ & Red & 10 & 1.51 & $0,45,90,135^{\circ} /$ le $(50)$ & $\mathrm{Lab} / \mathrm{le}$ & $40(61.5)$ & $25(38.5)$ \\
\hline
\end{tabular}

Distributions of retrogradely labeled neurons inside and outside the 2-DG-labeled orientation columns in the hemisphere contralateral to the injection sites. Explanations and abbreviations are as for Table 2 .
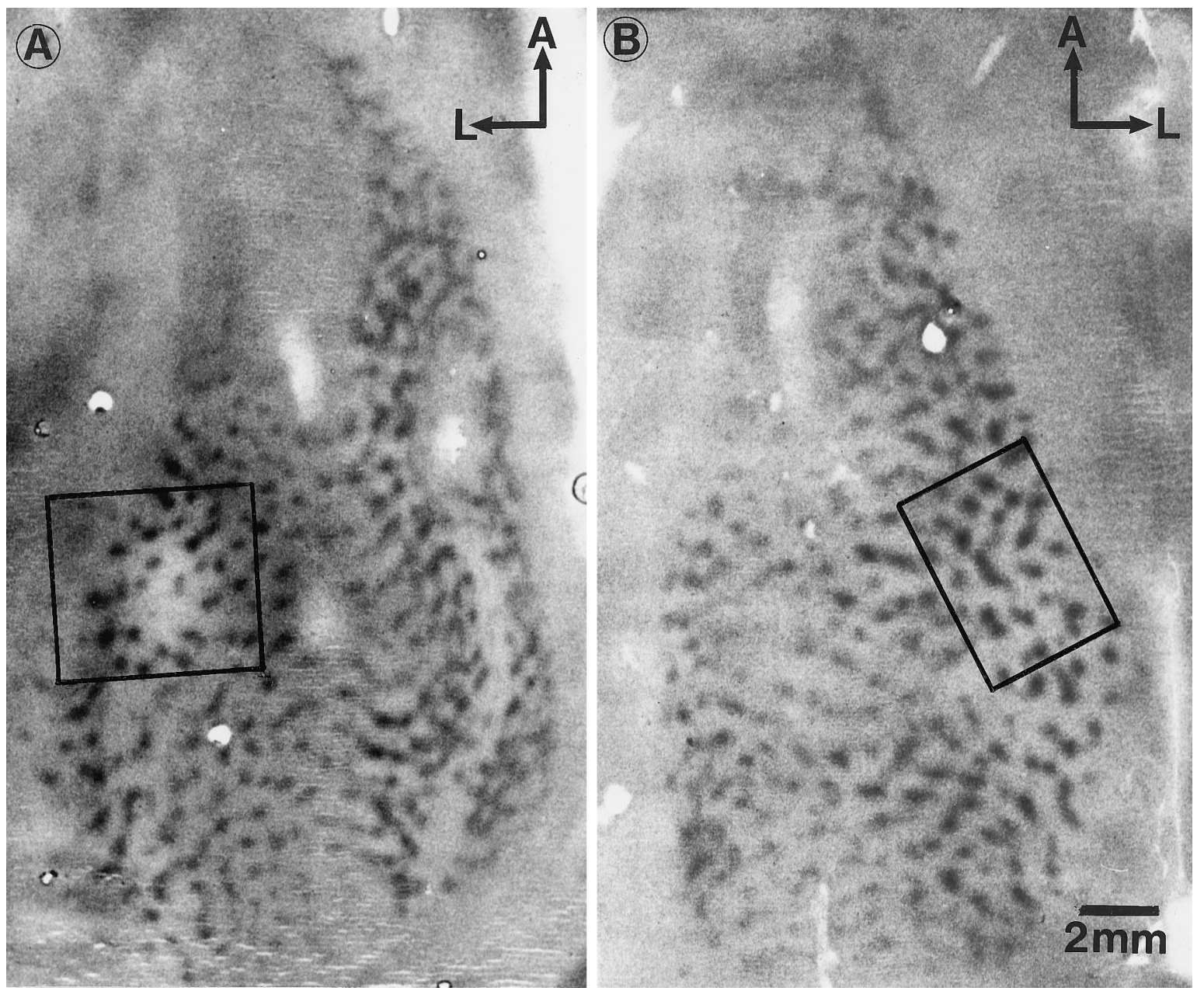

Figure 2. Layout of 2-DG-labeled monocular orientation domains in area 17 of a strabismic cat. Autoradiographs of flat-mounted sections from the unfolded left $(A)$ and right $(B)$ hemispheres of cat $\mathrm{C} 2$, the right eye of which had been stimulated with moving horizontal $\left(0^{\circ}\right)$ bars. $A$, The black frame indicates the injection sites within the representation of the central visual field in area 17 close to the 17/18 border. The cortical representation of the optical disk in the posterior third of area 17 (arrow) is devoid of 2-DG labeling (contralateral to the stimulated eye). $B$, Transcallosally labeled cells were found in the region of area 17 (black frame) that corresponds topographically to the injected area in the contralateral hemisphere. Cortical coordinates: $A$, anterior; $L$, lateral. Scale bar, $2 \mathrm{~mm}$.

injection $\mathrm{C} 6 /$ red was also discarded, because we had reasons to doubt that the injection was confined to a single orientation domain and to area 17 . Spillover to area 18 was suggested by the observation that $87 \%$ of the labeled geniculate neurons were in lamina $\mathrm{C}$. The injections in cat $\mathrm{CC}$ labeled neurons preferentially in geniculate lamina $\mathrm{A} 1$, indicating that they were located within territories of the nonstimulated left eye. In cat $\mathrm{CN}$ both the red and green injections led to retrograde labeling in all laminae, 
indicating injections of territories receiving input from both eyes. Retrogradely labeled neurons were found mainly in the central coronal sections of the LGN and were always located near the medial edges of both laminae $\mathrm{A}$ and $\mathrm{C}$. This indicates that injections were located in the central visual field representation of area 17 within a few degrees above and below the horizontal meridian (Kaas et al., 1972) and close to the vertical meridian (Sanderson, 1971). In addition, a considerable fraction of cells (22.5-63.7\%) was labeled in lamina C. Because the contribution of lamina $\mathrm{C}$ to the projection to area 17 increases toward the $17 / 18$ border (Holländer, 1977), this is further confirmation that the injections were located close to the vertical meridian.

\section{Functional topography of intrinsic horizontal connections in area 17}

An example of the labeling pattern in a strabismic cat after two cortical injections, targeted at the center of two neighboring domains dominated by the same eye and preferring horizontal contours, is illustrated in Figure $3 B$. Connections extended up to $5 \mathrm{~mm}$ from the injection sites. Comparison of the pattern of labeled cells with the corresponding 2-DG autoradiographs (Fig. $3 A$ ) showed that neurons labeled from both injection sites were located predominantly within territories that had the same ocular dominance and orientation preference (labeled regions) as cells at the injection sites (Fig. $3 C$ ). In some experiments, neurons filled with red microspheres were found within the column that had been injected with green beads and vice versa, indicating some reciprocity of the connections between columns. In addition, neurons labeled with red and neurons labeled with green beads were occasionally colocalized in the same columns. Another example of an injection in domains preferring an orientation of $45^{\circ}$ is shown in Figure 4.

For quantification of the topographic relationship between the patterns of retrogradely labeled neurons and 2-DG-labeled monocular orientation columns, the autoradiographs were subject to a thresholding procedure (see Materials and Methods) to obtain sharp boundaries between active and inactive regions. On average, $55.9 \pm 7.3 \%$ of the retrogradely labeled neurons were located in the active zones, i.e., in domains having the same eye and orientation preferences as the injection sites, irrespective of whether injections were placed in domains of the deviated (C4 and $\mathrm{C} 5)$ or nondeviated eye $(\mathrm{C} 1-\mathrm{C} 3)$. Figure 5 shows the corresponding data for normal cat $\mathrm{CN}$. The red injection of cat $\mathrm{CN}$, which was located in a horizontal orientation column with no eye specification, revealed that $56.0 \%$ of the retrogradely labeled neurons were localized in the respective iso-orientation domains. This percentage is similar to that found in strabismic cats. By contrast, only $20.8 \%$ of the neurons labeled from an injection of a vertical domain (green beads) were located in columns with preferences for horizontal contours.

Figure 6 summarizes the results from nine injections in strabismic cats and two injections in a normal cat before pooling the data, demonstrating that cell densities in the labeled and nonlabeled compartments do not overlap. Statistical analysis of distributions resulting from individual experiments (Table 2) confirmed that cell densities in columns sharing the ocular dominance and orientation preference of the injection site were significantly higher and, in case of cat $\mathrm{CN}$ (green), lower than expected from a random distribution $\left(\chi^{2}\right.$ test, $\left.p<0.001\right)$.

In normal cat $\mathrm{CC}$ both injections were localized in domains dominated by the left eye with no further orientation preference specification, and retrogradely labeled neurons did not show any significant preference for ocular dominance territories (see also Löwel and Singer, 1992). Averaged across sections, 59.9\% (green) and $54.1 \%$ (red) of the labeled cells were found within the domains dominated by the same eye as the injection site, which covered $50 \%$ of area 17 .

\section{Functional topography of interhemispheric connections}

In one normal (CC) and three strabismic (C2, C3, and C5) animals, injections were located close to the vertical meridian within area 17 and labeled callosally projecting neurons. Retrogradely filled cells were observed in the topographically corresponding parts of the contralateral hemispheres. Neurons were found in 7-12 consecutive sections, 550-800 $\mu \mathrm{m}$ from the cortical surface, which corresponds to lower layer III and layer IV. In accordance with previous observations (Innocenti and Caminiti, 1980), callosally projecting neurons seemed larger than neurons with intrinsic connections. The zone containing callosal neurons in the strabismic cats comprised on average $4.3 \pm 1.6$ isoorientation columns and extended on average $3 \pm 0.52 \mathrm{~mm}$ from the $17 / 18$ border into area 17 .

Superposition of the callosal cell patterns with the 2-DG labeled domains revealed that retrogradely labeled neurons are located preferentially in columns that have the same ocular dominance and orientation preference as the injection site in the contralateral hemisphere (Fig. 7). On average $60.4 \pm 11.8 \%$ of the retrogradely labeled neurons were located within the autoradiographically labeled monocular iso-orientation domains. The callosal cell distributions across eye dominance and orientation domains were very similar to the distributions on the ipsilateral side and differed maximally by $\pm 6.5 \%$ per injection (see Table 3 ). In three of six cases ( $\mathrm{C} 2$, green and red; $\mathrm{C} 3$, green), the bias for neurons to be located within domains with the same functional properties was highly significant $(p<0.005)$. In case C5 (green), however, this bias did not reach statistical significance $(p>0.05)$, although the ratios between cells in labeled and unlabeled domains were very similar to those in the ipsilateral hemisphere of the same animal, in which the bias was highly significant. We attribute this lack of statistical significance to the small number of labeled callosal neurons. The same explanation holds with all likelihood for the lower level of significance $(p<0.01)$ in cases C3 (red) and C5 (red). No differences were noted between distributions resulting from injections in domains of the normal (C2 and C3) and deviated (C5) eye. Thus, in strabismic cats, not only tangential intracortical but also callosal connections link predominantly territories that share the same ocular dominance and orientation preference, irrespective of whether the territories are dominated by the normal or the deviated eye.

The distributions of transcallosally labeled neurons in normal cat CC failed to show a preference for ocular dominance domains (but see Olavarria, 1996). On average $60.9 \%$ of the retrogradely labeled neurons were located within domains activated by the left eye, which in this case covered $50 \%$ of the cortical surface rather than $30 \%$, because the cat had experience with all orientations.

\section{DISCUSSION}

\section{Methodological considerations}

For quantitative analysis, the autoradiographs of the cats stimulated monocularly with a single orientation were subject to a thresholding procedure that restricted domains controlled by the same eye and preferring the same orientation to $30 \%$ of the cortical surface. This threshold was selected because the gray 


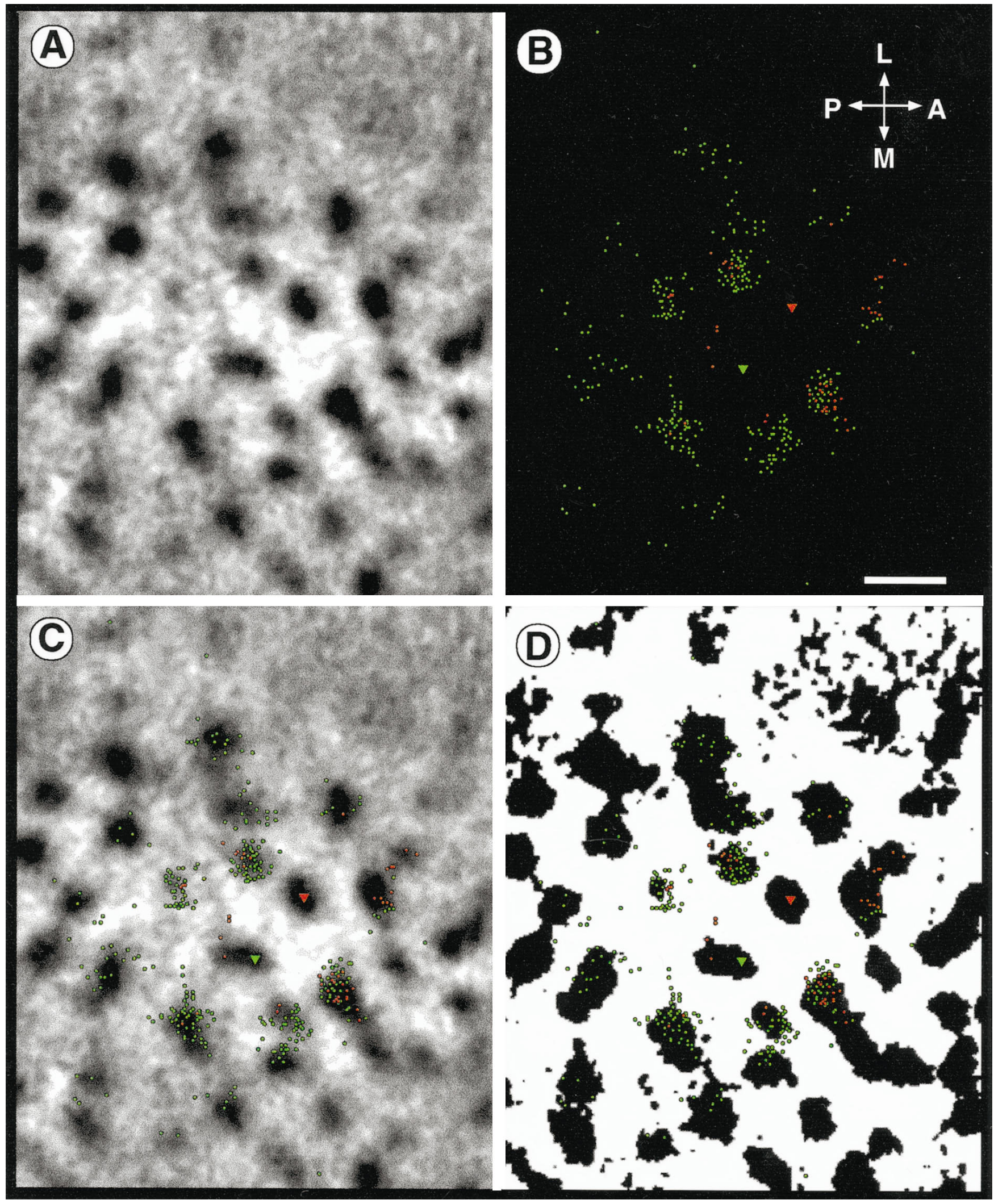

Figure 3. Topographic relations between intrinsic horizontal connections and monocular orientation domains in area 17 of cat C2. $A$, Enlarged detail of the 2-DG autoradiograph of Figure $2 A$ showing the region within the black frame (Fig. $2 A$ ) that contained the injections and the labeled neurons. $B$, Patchy distribution of retrogradely labeled cells within the same region. Neurons labeled with rhodamine $(n=50)$ and fluorescein beads $(n=303)$ are represented by red and green dots. Injection sites are marked by triangles. $C$, Superposition of $A$ and $B$ with the help of three landmarks (see Fig. $1 A$ ). Both injections are localized in dark columns of the same functional preference $\left(0^{\circ}\right.$, right eye). $D$, Superposition of labeled neurons on the contrast-enhanced autoradiograph. Note that the cells are predominantly localized in the 2-DG-labeled domains (dark areas) and thus in regions having similar eye and orientation preference as the injection sites. Abbreviations are as in Figure 1. Scale bar, $1 \mathrm{~mm}$. 


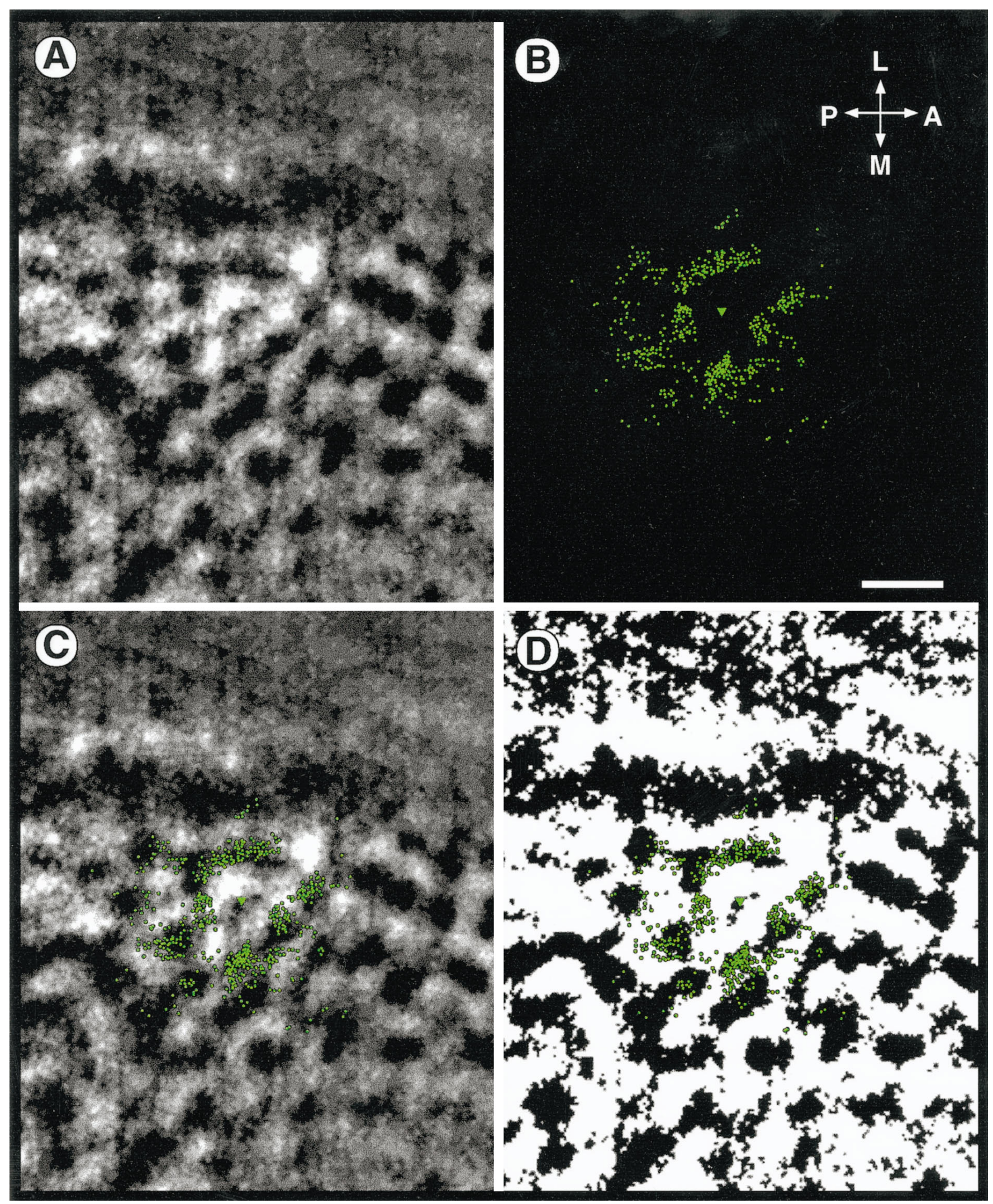

Figure 4. Topographic relations between intrinsic horizontal connections and monocular orientation domains in area 17 of cat C5 (green). $A$, Enlarged detail of the 2-DG autoradiograph around the injection site. $B$, Patchy distribution of retrogradely labeled cells within the same region. Neurons labeled with fluorescein beads $(n=534)$ are represented by green dots; the injection site is indicated by the green triangle. $C$, Superposition of $A$ and $B$ with the help of three landmarks (see Fig. $1 A$ ). $D$, Superposition of labeled neurons on the contrast-enhanced autoradiograph. Note that the cells are predominantly localized in the 2-DG-labeled domains (dark areas) and thus in regions having similar eye (left) and orientation preferences $\left(45^{\circ}\right)$ as the injection site. Abbreviations are as in Figure 1. Scale bar, $1 \mathrm{~mm}$. 


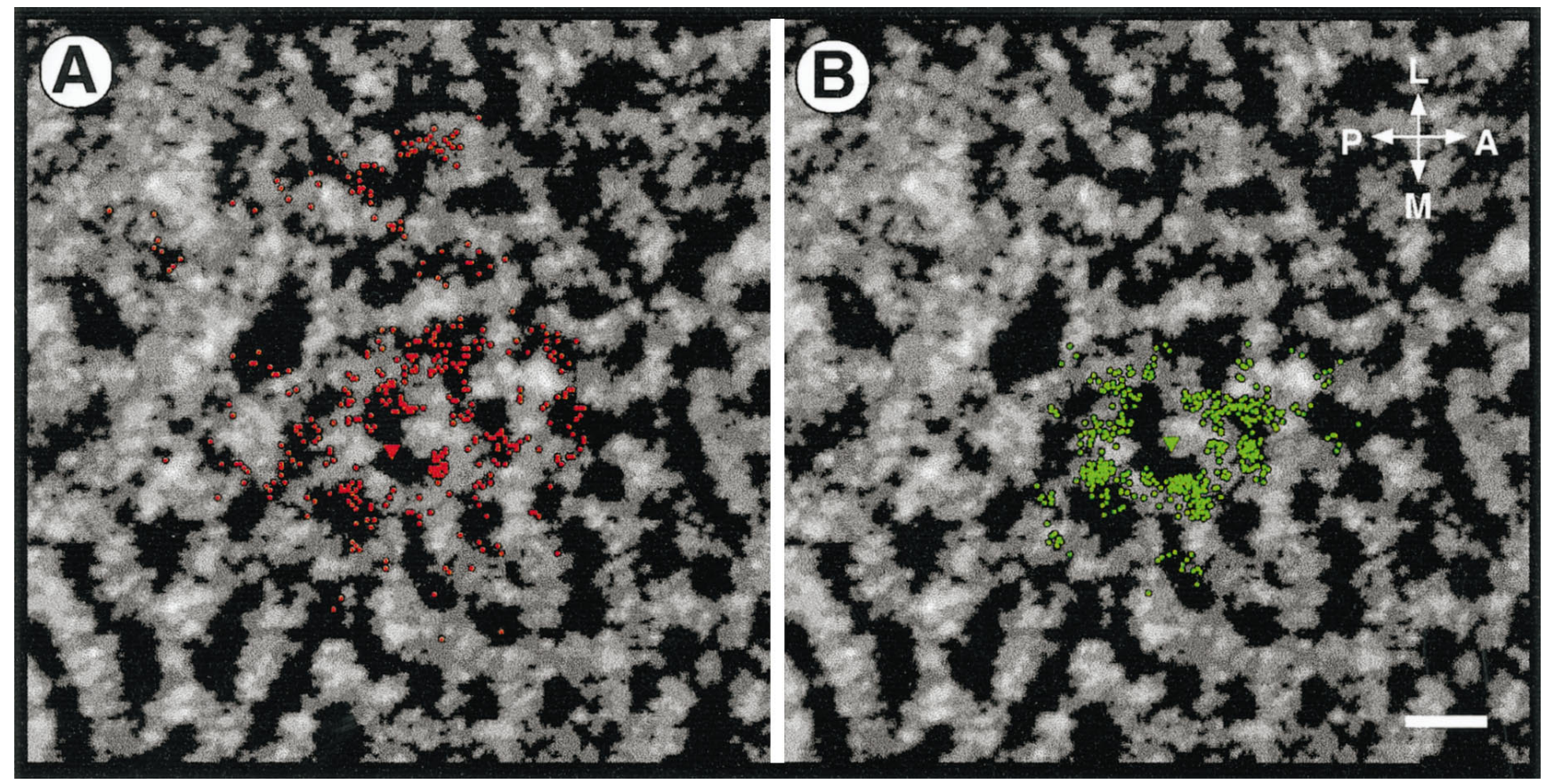

Figure 5. Superposition of retrogradely labeled neurons and 2-DG-labeled horizontal orientation columns in normal cat CN. $A$, An injection of red microspheres was made in a column of neurons preferring horizontal contours. Of the labeled neurons, $54.6 \%(n=414)$ are localized in iso-orientation domains. $B$, Distribution after an injection of green microspheres in a column preferring vertical contours. Only $22 \%$ of the labeled cells $(n=360)$ are localized in the labeled horizontal orientation domains. Scale bar, $1 \mathrm{~mm}$. Abbreviations are as in Figure 1.

value histograms of all investigated autoradiographs showing orientation columns in both strabismic and normal cats had their turning point at this particular value (see Materials and Methods). Assuming that the neuronal population in strabismic cats is split into two equally large monocular populations and that orientation preferences are distributed equally, the defined area $(30 \%)$ is likely to include neurons with orientation preferences that differ by as much as $45^{\circ}$ from the orientation of the grating used for activation. Moreover, labeled domains might contain some binocular neurons, because in cats with divergent squint about $7 \%$ of the neurons remain responsive to both eyes (Kalil et al., 1984). Because in normal cats most neurons are binocular, the defined area of $30 \%$ in cat $\mathrm{CN}$ should include orientation preferences in a range of $27^{\circ}$.

It has been shown previously that orientation maps as revealed with the 2-DG method or with optical imaging reflect precisely the topology of electrophysiologically determined orientation columns (Schoppmann and Stryker, 1981; Grinvald et al., 1986). Our present results confirm the perfect match between the activation patterns obtained with optical imaging and the 2-DG technique (data not shown).

We based our superpositions on the 2-DG rather than the optical-imaging maps, because this allowed for a direct correlation between cell locations and columnar patterns in the same flat-mounted sections, circumventing problems related to distortion and shrinkage of sections attributable to histological procedures.

\section{Layout of monocular iso-orientation domains in strabismic cats}

The 2-DG maps provide direct evidence that squint had caused the expected disruption of cortical binocularity because, in contrast to normally reared cats (Löwel and Singer, 1993a), there was a consistent lack of labeling at the representation of the optic disk in the hemisphere contralateral to the stimulated eye (Löwel and Singer, 1992, 1993b). No obvious differences were noted, however, between the 2-deoxyglucose patterns evoked by stimulation of either the deviated or the nondeviated eye. This is consistent with electrophysiological evidence from strabismic cats, which suggests that neurons driven from the normal and deviated eyes have similar and normal orientation tuning (Hubel and Wiesel, 1965; Freeman and Tsumoto, 1983; Kalil et al., 1984; Sengpiel et al., 1994).

\section{Intrinsic connections}

In the strabismic cats, on average $56 \%$ of the labeled neurons were located in territories sharing the ocular dominance and orientation preference of the injection site. Because these regions occupied only $30 \%$ of the cortical surface, this suggests that the tangential connections have preserved their tendency to interconnect preferentially domains with similar orientation preference, although they had segregated into eye-specific subnetworks because of squint (Löwel and Singer, 1992). The selectivity for iso-orientation domains is comparable to that described for horizontal connections in area 17 of normally raised cats $(\mathrm{CN}$ red, $60.4 \%$ ) and macaque monkeys (Gilbert and Wiesel, 1989; Malach et al., 1993). The quantitative analysis of Malach et al. (1993) showed that $66 \%$ of the interconnected neurons in area 17 share preferences for orientations that differ by less than $\pm 45^{\circ}$. This value cannot be compared directly with our results, because we investigated the joint probability $\left(p_{\text {ODOR }}\right)$ of connections to link neurons that have the same ocular dominance (OD) and orientation preference (OR). In strabismic cats connections had a probability to be eye-specific $\left(p_{\text {OD }}\right)$ of $86 \pm 5 \%$ (Löwel and Singer, 1992). Based on this value it is possible to estimate the probability of additional orientation selectivity $\left(p_{\mathrm{OR}}\right)$ according to the formula $p_{\mathrm{OR}}=p_{\mathrm{ODOR}} / p_{\mathrm{OD}}$. This yields a $p_{\mathrm{OR}}$ value of $70 \%$ for our animals. Thus, the tendency of intrinsic connections to 

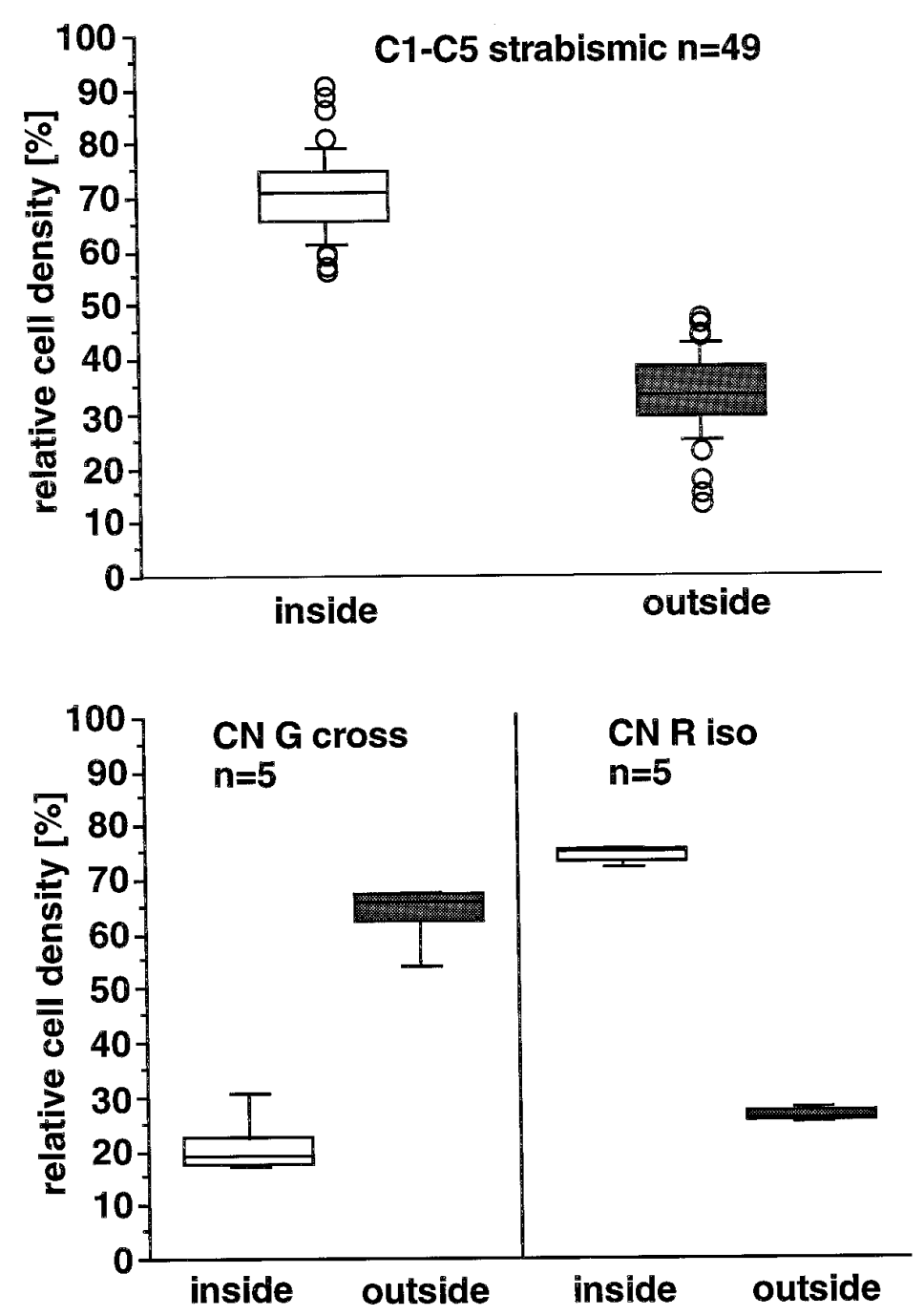

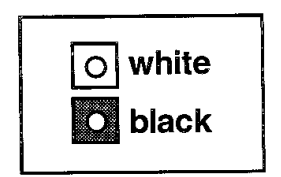

Figure 6. Box plot summarizing the normalized distributions of labeled neurons (cell densities) within injected area 17 for all analyzed sections (strabismic cats, $n=$ 49; normal cat, red injection, $n=5$; green injection, $n=5$ ) of nine injections in strabismic cats and two injections in a normal cat. Distributions are calculated on a $100 \%$ scale: the sum of labeled neurons (density) within black (2-DG-labeled) and white nonlabeled compartments adds to $100 \%$. Ordinate, Normalized density of cells in the respective compartment in percent. The horizontal line within each box represents the mean. The 10th, 25th, 50th, 75th, and 90th percentiles of these distributions are displayed as horizontal lines. Outliers below the 10th and above the 90th percentiles are plotted as open circles. Note that the distributions in the two compartments do not overlap. link neurons with similar orientation preference is at least as high in strabismic cats as it is in monkey V1, suggesting that squint had not interfered with this feature.

This finding is compatible with the notion that the selection criterion for the stabilization of tangential connections is the correlation among the responses of interconnected neurons (Löwel and Singer, 1992). Because monocular vision is unimpaired in strabismic animals, correlations among neurons dominated by the same eye are expected to be the same as in normal cats.

This of course does not exclude the possibility that the initial layout of connections gets specified by experience-independent factors such as biochemical markers (Meinhard and Gierer, 1980; Edelman and Cunningham, 1990) and for self-generated, patterned activity (for recent review, see Katz and Shatz, 1996). The basic organization of orientation maps (Chapman et al., 1996; Goedecke and Bonhoeffer, 1996; Ruthazer and Stryker, 1996) and of both intrinsic and callosal connections (Chalupa and Dreher, 1991) specified before visual experience becomes effective and supports further refinement of connectivity patterns. Thus, Aggoun-Zouaoui et al. (1996) have reported a columnar ingrowth of callosal axons into the cortex already toward the end of the first postnatal week. These authors encountered difficulties in relating these initial immature structures to the adult terminal columns and assume a vision-dependent validation process that goes in parallel with the formation and elongation of branches and further synaptogenesis.

\section{Callosal connections}

The present results revealed striking similarities between the organization of tangential intrinsic and transcallosal connections. The only difference was that the selectivity of callosal connections with respect to eye dominance and orientation domains was statistically less significant than that of intrinsic connections. However, this was not attributable to reduced selectivity but to the smaller sample size. Callosal fibers interconnect neurons sharing the same ocular dominance and orientation preference with almost similar selectivity as the intrinsic connections, so that they seem to be equally susceptible to the effects of squint. This agrees with previous suggestions that interhemispheric and intrahemispheric connections serve similar functions and should therefore be organized similarly (Hubel and Wiesel, 1967; Innocenti, 1986). However, because of the weaker statistics the possibility needs to be considered that callosal connections are more heterogeneous than intrinsic connections and that subpopulations of callosal fibers obey other rules.

Earlier studies on callosal projections of sensory, motor, and association areas in several species described rather heteroge- 


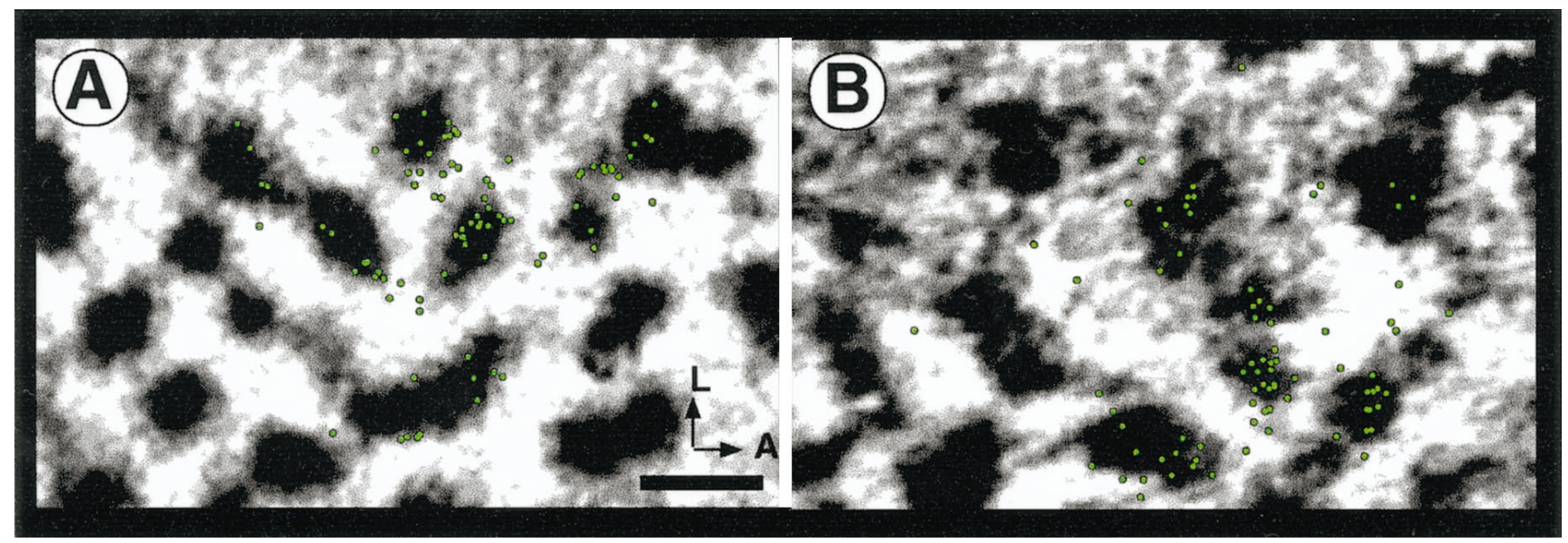

Figure 7. Topographic relations between transcallosally labeled neurons and monocular orientation domains in right area 17 of cats $\mathrm{C} 2(A)$ and $\mathrm{C} 3(B)$. Superposition of retrogradely labeled neurons ( green dots) and the monocular 2-DG patterns evoked by right eye stimulation with horizontal contours. Note that neurons are preferentially confined to the 2-DG-labeled columns (dark regions). Because of the relatively low density of callosally projecting neurons, cells from six $(A, n=88)$ and five $(B, n=104)$ adjacent sections were summed and superimposed on the corresponding 2-DG autoradiographs. $A$, Enlarged detail of the area indicated by the black frame in Figure $2 B$. Scale bar, $1 \mathrm{~mm}$. Abbreviations are as in Figure 1 .

neous columnar patterns with "column" diameters ranging from 200 to $1000 \mu \mathrm{m}$ (for review, see Innocenti, 1986; i.e., for striate cortex, Berman and Payne, 1983; Voigt et al., 1988; Payne and Siwek, 1991; Houzel et al., 1994; extrastriate cortex, Segraves and Rosenquist, 1982).

Evidence indicates that the columnar pattern of callosal connections in the primary auditory cortex is related to "ear dominance bands" (Imig and Brugge, 1978), but the functional significance of the columnar pattern of visual callosal projections remained unclear, although a relation to orientation columns (Innocenti, 1986; Voigt et al., 1988; Houzel et al., 1994), ocular dominance bands (Payne and Siwek, 1991; Olavarria, 1996), and cytochrome oxidase-positive patches (Boyd and Matsubara, 1994) had been suggested.

The present data agree with the physiological evidence that callosal connections link cells with receptive fields that have similar positions and matching orientation and direction preferences (Berlucchi and Rizzolatti, 1968; Lepore and Guillemot, 1982; Blakemore et al., 1983; Lepore et al., 1986). Callosal connections are not only contributing to the formation of ipsilaterally extending receptive fields, but they also synchronize the responses of neurons located in the two hemispheres (Engel at al., 1991; Munk et al., 1995). The strongest and most precise synchronization ("T peak") occurs for responses of neurons that have overlapping receptive fields and similar orientation preferences (Engel et al., 1991; Nowak et al., 1995), which is in agreement with the topology of callosal connections revealed in the present study.

In young kittens, callosally projecting neurons are not confined to the representation of the vertical meridian but distribute across the entire area 17 (Innocenti et al., 1977; Innocenti and Caminiti, 1980). Early strabismus, monocular deprivation, and short periods of binocular deprivation interfere with the developmental process that eventually confines the callosal projection zone to the vertical meridian, so that callosally projecting neurons come to occupy a broader strip along the 17/18 border (Innocenti and Frost, 1979; Berman and Payne, 1983; Elberger et al., 1983). Our data (see Table 3) do not allow us to determine whether this had also occurred in the present experiments, because there are not enough control data from normal cats with comparably small injections. However, our results indicate that callosal connections are influenced by strabismus and in exactly the same way as the tangential intracortical connections. They came to link selectively territories dominated by the same eye (but see Olavarria, 1996). Thus, the development of the interhemispheric pathway is likely to be governed by similar experience-dependent organizing principles as described previously for the long-range intracortical connections; neurons exhibiting decorrelated activation patterns lose their corticocortical connections.

\section{REFERENCES}

Aggoun-Zouaoui D, Kiper DC, Innocenti GM (1996) Growth of callosal terminal arbors in primary visual areas of the cat. Eur J Neurosci 8:1132-1148.

Albus K (1979) ${ }^{14} \mathrm{C}$-Deoxyglucose mapping of orientation subunits in the cat's visual cortical areas. Exp Brain Res 37:609-613.

Allman J, Miezin F, McGuiness E (1985) Stimulus specific responses from beyond the classical receptive field: neurophysiological mechanisms for local-global comparisons in visual neurons. Annu Rev Neurosci 7:407-430.

Berlucchi G, Rizzolatti G (1968) Binocularly driven neurons in visual cortex of split-chiasm cats. Science 159:308-310.

Berman N, Payne BR (1983) Alterations in connections of the corpus callosum following convergent and divergent strabismus. Brain Res 274:201-212.

Blakemore C, Tobin EA (1972) Lateral inhibition between orientation detectors in the cat's visual cortex. Exp Brain Res 15:439-440.

Blakemore C, Diao Y, Pu M, Wang Y, Xiao Y (1983) Possible functions of interhemispheric connections between visual cortical areas in the cat. J Physiol (Lond) 337:331-348.

Bolz J, Gilbert CD (1990) The role of horizontal connections in generating long receptive fields in the cat visual cortex. Eur J Neurosci 1:263-268

Bonhoeffer T, Grinvald A (1993) The layout of iso-orientation domains in area 18 of cat visual cortex: optical imaging reveals a pinwheel-like organization. J Neurosci 13:4157-4180.

Boyd J, Matsubara J (1994) Tangential organization of callosal connectivity in the cat's visual cortex. J Comp Neurol 347:197-210.

Callaway EM, Katz LC (1990) Emergence and refinement of clustered intrinsic connections in cat striate cortex. J Neurosci 10:1134-1153.

Callaway EM, Katz LC (1991) Effects of binocular deprivation on the development of clustered horizontal connections in cat striate cortex. Proc Natl Acad Sci USA 88:745-749.

Chalupa LM, Dreher B (1991) High precision systems require high precision "blueprints": a new view regarding the formation of connections in the mammalian visual system. J Cogn Neurosci 3:209-219. 
Chapman B, Stryker MP, Bonhoeffer T (1996) Development of orientation preference maps in ferret primary visual cortex. J Neurosci 16:6443-6453.

Cynader M, Lepore F, Guillemot JP (1981) Inter-hemispheric competition during postnatal development. Nature 290:139-140.

Darian-Smith C, Gilbert CD (1994) Axonal sprouting accompanies functional reorganization in adult striate cortex. Nature 368:737-740.

Edelman GM, Cunningham BA (1990) Place-dependent cell adhesion, process retraction, and spatial signaling in neural morphogenesis. Cold Spring Harb Symp Quant Biol 55:303-318.

Elberger A, Smith EL, White JM (1983) Spatial dissociation of visual inputs alters the origin of the corpus callosum. Neurosci Lett 35:19-24.

Engel AK, König P, Kreiter AK, Singer W (1991) Interhemispheric synchronization of oscillatory neuronal responses in cat visual cortex. Science 252:1177-1179.

Eysel UT, Crook JM (1990) GABA-induced remote inactivation reveals cross-orientation inhibition in the cat striate cortex. Exp Brain Res 80:626-630.

Eysel UT, Wörgötter F, Pape H-C (1987) Local cortical lesions abolish lateral inhibition in the cat striate cortex. Exp Brain Res 68:606-612.

Fisken RA, Garey LJ, Powell TPS (1975) The intrinsic, association and commissural connections of area 17 of the visual cortex. Philos Trans R Soc Lond [Biol] 272:487-536.

Freeman B, Löwel S, Singer W (1987) Deoxyglucose mapping in the cat visual cortex following carotid artery injection and cortical flatmounting. J Neurosci Methods 20:115-129.

Freeman RD, Tsumoto T (1983) An electrophysiological comparison of convergent and divergent strabismus in the cat: electrical and visual activation of single cortical cells. J Neurophysiol 49:238-253.

Galuske RAW, Singer W (1996) The origin and topography of long range intrinsic projections in cat visual cortex: a developmental study. Cereb Cortex 6:417-430.

Gilbert CD, Wiesel TN (1983) Clustered intrinsic connections in cat visual cortex. J Neurosci 3:1116-1133.

Gilbert CD, Wiesel TN (1985) Intrinsic connectivity and receptive field properties in visual cortex. Vision Res 25:365-374.

Gilbert CD, Wiesel TN (1989) Columnar specificity of intrinsic horizontal connections in cat visual cortex. J Neurosci 9:2432-2442.

Gilbert CD, Wiesel TN (1992) Receptive field dynamics in primary visual cortex. Nature 356:150-152.

Gödecke I, Bonhoeffer T (1996) Development of identical orientation maps for two eyes without common visual experience. Nature 379:251-254.

Gray CM, König P, Engel AK, Singer W (1989) Oscillatory responses in cat visual cortex exhibit inter-columnar synchronization which reflects global stimulus properties. Nature 338:334-337.

Grinvald A, Lieke E, Frostig RD, Gilbert CD, Wiesel TN (1986) Functional architecture of cortex revealed by optical imaging of intrinsic signals. Nature 324:361-364.

Halasz P, Martin PR (1984) A microcomputer based system for semiautomatic analysis of histological sections. Proc R Microsc Soc 19:312.

Hata Y, Tsumoto T, Sato H, Tamura H (1991) Horizontal interactions between visual cortical neurons studied by cross-correlation analysis in the cat. J Physiol (Lond) 441:593-614.

Heinen SJ, Skavenski AA (1991) Recovery of visual responses in foveal V1 neurons following bilateral foveal lesions in adult monkey. Exp Brain Res 83:670-674.

Holländer H (1977) The projection from the lateral geniculate nucleus onto the visual cortex in the cat. A quantitative study with horseradish peroxidase. J Comp Neurol 173:519-536.

Horsley V, Clarke RH (1908) The structure and functions of the cerebellum examined by a new method. Brain 31:45-124.

Houzel J-C, Milleret C, Innocenti G (1994) Morphology of callosal axons interconnecting areas 17 and 18 of the cat. Eur J Neurosci 6:898-917.

Hubel DH, Wiesel TN (1965) Binocular interaction in striate cortex of kittens reared with artificial squint. J Neurophysiol 28:1041-1059.

Hubel DH, Wiesel TN (1967) Cortical and callosal connections concerned with the vertical meridian of visual fields in the cat. J Neurophysiol 30:1561-1573.

Imig TJ, Brugge JF (1978) Sources and terminations of callosal axons related to binaural and frequency maps in primary auditory cortex of the cat. J Comp Neurol 182:637-660.

Innocenti GM (1986) General organization of callosal connections in the cerebral cortex. In: Cerebral cortex, Vol 5 (Peters A, Jones EG, eds), pp 291-353. New York: Plenum.

Innocenti GM, Caminiti R (1980) Postnatal shaping of callosal connections from sensory areas. Exp Brain Res 38:381-394.

Innocenti GM, Frost DO (1979) Effects of visual experience on the maturation of the efferent system to the corpus callosum. Nature 280:231-234.

Innocenti GM, Fiore L, Caminiti R (1977) Exuberant projection into the corpus callosum from the visual cortex of newborn cats. Neurosci Lett 4:237-242.

Kaas JH, Guillery RW, Allman JM (1972) Some principles of organization in the dorsal lateral geniculate nucleus. Brain Behav Evol 6:253-299.

Kaas JH, Krubitzer LA, Chino YM, Langston AL, Polley EH, Blair N (1990) Reorganization of retinotopic cortical maps in adult mammals after lesions of the retina. Science 248:229-231.

Kalil RE, Spear PD, Langsetmo A (1984) Response properties of striate cortex neurons in cats raised with divergent or convergent strabismus. J Neurophysiol 52:514-537.

Katz LC, Iarovici DM (1990) Green fluorescent latex microspheres: a new retrograde tracer. Neuroscience 34:511-520.

Katz LC, Shatz CJ (1996) Synaptic activity and the construction of cortical circuits. Science 274:1133-1138.

Katz LC, Burkhalter A, Dreyer WJ (1984) Fluorescent latex microspheres as a retrograde neuronal marker for in vivo and in vitro studies of visual cortex. Nature 310:498-500.

Kisvárday ZF, Eysel UT (1992) cellular organization of reciprocal patchy networks in layer III of cat visual cortex (area 17). Neuroscience 46:275-286.

König P, Engel AK, Löwel S, Singer W (1993) Squint affects synchronization of oscillatory responses in cat visual cortex. Eur J Neurosci 5:501-508.

Lepore F, Guillemot J-P (1982) Visual receptive field properties of cells innervated through the corpus callosum in the cat. Exp Brain Res 46:413-424.

Lepore F, Ptito M, Guillemot J-P (1986) The role of the corpus callosum in midline fusion. In: Two hemispheres-one brain (Lepore F, Ptito M, Jasper HH, eds), pp 211-229. New York: Alan R Liss.

Livingstone MS, Hubel DH (1984) Specificity of intrinsic connections in primate visual cortex. J Neurosci 4:2830-2835.

Löwel S (1994) Ocular dominance column development: strabismus changes the spacing of adjacent columns in cat visual cortex. J Neurosci 14:7451-7468.

Löwel S, Singer W (1992) Selection of intrinsic horizontal connections in the visual cortex by correlated neuronal activity. Science 255:209-212.

Löwel S, Singer W (1993a) Monocularly induced 2-deoxyglucose patterns in the visual cortex and lateral geniculate nucleus of the cat: 1 . Anaesthetized and paralyzed animals. Eur J Neurosci 5:846-856.

Löwel S, Singer W (1993b) Monocularly induced 2-deoxyglucose patterns in the visual cortex and lateral geniculate nucleus of the cat: 2 . Awake animals and strabismic animals. Eur J Neurosci 5:857-869.

Löwel S, Freeman B, Singer W (1987) Topographic organization of the orientation column system in large flat-mounts of the cat visual cortex: a 2-deoxyglucose study. J Comp Neurol 255:401-415.

Luhmann HJ, Martinez-Millan L, Singer W (1986) Development of horizontal intrinsic connections in cat striate cortex. Exp Brain Res 63:443-448.

Luhmann HJ, Singer W, Martinez-Millan L (1991) Horizontal interactions in cat striate cortex: I. Anatomical substrate and postnatal development. Eur J Neurosci 2:358-368.

Lund RD, Mitchell DE, Henry GH (1978) Squint-induced modification of callosal connections in cats. Brain Res 144:169-172.

Malach R, Amir Y, Harel M, Grinvald A (1993) Relationship between intrinsic connections and functional architecture revealed by optical imaging and in vivo targeted biocytin injections in primate striate cortex. Proc Natl Acad Sci USA 90:10469-10473.

Malach R, Tootell RBH, Malonek D (1994) Relationship between orientation domains, cytochrome oxidase stripes, and intrinsic horizontal connections in squirrel monkey area V2. Cereb Cortex 4:151-165.

Meinhard M, Gierer A (1980) Generation and regeneration of sequences of structures during morphogenesis. J Theor Biol 85:429-450.

Morrone MC, Burr DC, Maffei L (1982) Functional implications of cross-orientation inhibition of cortical visual cells. I. Neurophysiological evidence. Proc R Soc Lond [Biol] B216:335-354. 
Munk MHJ, Nowak LG, Nelson JI, Bullier J (1995) The structural basis of cortical synchronization. 2. Effects of cortical lesions. J Neurophysiol 74:2401-1414.

Nelson JI, Frost BJ (1978) Orientation-selective inhibition from beyond the classical receptive field. Exp Brain Res 139:359-365.

Nowak LG, Munk MJH, Nelson JI, James AC, Bullier J (1995) The structural basis of cortical synchronization. 1. Three types of interhemispheric coupling. J Neurophysiol 74:2379-2400.

Olavarria JF (1996) Visual callosal fibers link cortical columns dominated by the same eye in the cat. Soc Neurosci Abstr 22:491.

Olson CR, Freeman RD (1978) Development of eye alignment in cats. Nature 271:446-447.

Payne BR, Siwek DF (1991) Visual-field map in the callosal recipient zone at the border between areas 17 and 18 in the cat. Vis Neurosci 7:221-236.

Price DJ (1986) The postnatal development of clustered intrinsic connections in area 18 of the visual cortex in kittens. Dev Brain Res 24:31-38.

Rockland KS (1985) Anatomical organization of primary visual cortex (area 17) in the ferret. J Comp Neurol 241:225-236.

Rockland KS, Lund JS (1982) Widespread periodic intrinsic connections in the tree shrew visual cortex. Science 215:1532-1534.

Rockland KS, Lund JS (1983) Intrinsic laminar lattice connections in primate visual cortex. J Comp Neurol 216:303-318.

Ruthazer ES, Stryker MP (1996) The role of activity in the development of long-range horizontal connections in area 17 of the ferret. J Neurosci $16: 7253-7269$.

Sanderson KJ (1971) The projection of the visual field to the lateral geniculate and medial interlaminar nuclei in the cat. J Comp Neurol 143:101-118.

Schoppmann A, Stryker MP (1981) Physiological evidence that the 2-deoxyglucose method reveals orientation columns in cat visual cortex. Nature 293:574-576.
Schwarz C, Bolz J (1991) Functional specificity of a long-range connection in cat visual cortex: a cross-correlation study. J Neurosci 11:2995-3007.

Segraves MA, Rosenquist AC (1982) The distribution of cells of origin of callosal projections in cat visual cortex. J Neurosci 2:1079-1089.

Sengpiel F, Blakemore C, Kind PC, Harrad R (1994) Interocular suppression in visual cortex of strabismic cats. J Neurosci 14:6855-6871.

Shatz CJ, Lindström TN, Wiesel TN (1977) The distribution of afferents representing the right and the left eyes in the cat's visual cortex. Brain Res 131:103-116.

Sherman SM (1972) Development of interocular alignment in cats. Brain Res 37:187-203.

Singer W (1981) Topographic organization of orientation columns in the cat visual cortex. A deoxyglucose study. Exp Brain Res 44:431-436.

Singer W (1993) Synchronization of cortical activity and its putative role in information processing and learning. Annu Rev Physiol 55:349-374.

Singer W, Tretter F (1976) Unusually large receptive fields in cats with restricted visual experience. Exp Brain Res 26:171-184.

Sireteanu R, Singer W, Fronius M, Greuel JM, Best J, Fiorentini A, Bisti S, Schiavi C, Campos E (1993) Eye alignment and cortical binocularity in strabismic kittens: a comparison between tenotomy and recession. Vis Neurosci 10:541-549.

Ts'o D, Gilbert CD (1988) The organization of chromatic and spatial interactions in the primate striate cortex. J Neurosci 8:1712-1727.

Ts'o D, Gilbert CD, Wiesel TN (1986) Relationships between horizontal interactions and functional architecture in cat striate cortex as revealed by cross-correlation analysis. J Neurosci 6:1160-1170.

Voigt T, LeVay S, Stamnes MA (1988) Morphological and immunocytochemical observations in the visual callosal projections in the cat. J Comp Neurol 272:450-460.

von Grünau MW (1979) The role of maturation and visual experience in the development of eye alignment in cats. Exp Brain Res 37:41-47. 